Original article

\title{
Correlation and adaptation among functional and cognitive instruments for staging and monitoring Alzheimer's disease in advanced stages
}

\section{Adaptação e correlação entre instrumentos cognitivos e funcionais para o estadiamento e acompanhamento da doença de Alzheimer em fases avançadas}

\author{
José Roberto Wajman¹, Rodrigo Rizek Schultz, Sheilla de Medeiros Correia Marin¹, \\ Paulo Henrique Ferreira Bertolucci ${ }^{1}$
}

1 Ambulatório de Demência Grave, Núcleo de Envelhecimento Cerebral, Setor de Neurologia do Comportamento da Disciplina de Neurologia e Neurocirurgia, Universidade Federal de São Paulo (Unifesp), São Paulo, SP, Brasil.

Received: 8/13/2013 - Accepted: 11/17/2013

\begin{abstract}
Background: Although Alzheimer's disease (AD) is the most prevalent form of dementia, little is known about cognitive and functional aspects in its advanced stages. Objective: This study aimed the adaptation and correlation among specific instruments for AD in advanced stages with regard to cognition objectively weighted, besides the comparison between static and ecological aspects of functional capacity. Methods: 95 moderate, moderatly severe and severe AD patients (33 men and 62 women) underwent the scales CDR (Clinical for Dementia Rating), FAST (Functional Assessment Scale), MMSE (Mini-Mental State Exame), MMSEsev (Severe Mini-Mental State Examination), SIB-8 (Severe Impairment Battery) and TSI (Test for Severe Impairment), for the comparison with a golden-standard ecological scale the PADL (Performance Activities of Daily Living). Results: The evidence suggests an increasing and statistically significant linear correlation between the ecological functional scale and cognitive tests according to the stratification of AD stages once weighted by static functional scale. Discussion: The results indicate that for patients in advanced stages of $\mathrm{AD}$, appropriate cognitive tests and performance-based functional scales are useful in more accurate assessment of disease staging and monitoring its progression.
\end{abstract}

Wajman JR, et al. / Rev Psiq Clín. 2014;41(1):5-8

Keywords: Alzheimer's disease, dementia, cognition, functional capacity.

\section{Resumo}

Contexto: Apesar de a doença de Alzheimer (DA) ser a forma de demência mais prevalente, pouco se sabe sobre aspectos cognitivos e funcionais em suas fases avançadas. Objetivo: Foi objetivo deste trabalho a adaptação e correlação entre instrumentos específicos para a DA em fases avançadas no que diz respeito à sua cognição objetivamente ponderada, além da comparação entre aspectos da capacidade funcional estática e ecológica. Métodos: Noventa e cinco pacientes (33 homens e 62 mulheres) com DA moderada, moderadamente grave e grave foram submetidos às escalas CDR (Clinical for Dementia Rating), FAST (Functional Assessment Scale), MEEM (Mini-Mental State Examination), MMSEsev (Severe Mini-Mental State Examination), SIB-8 (Severe Impairment Battery) e TSI (Test for Severe Impairment) para comparação com uma escala ecológica padrão-ouro, a PADL (Performance Activities of Daily Living). Resultados: As evidências encontradas sugerem uma correlação linear crescente e estatisticamente significativa entre a escala funcional ecológica e os testes cognitivos conforme a estratificação das fases da DA uma vez ponderadas pela escala funcional estática. Conclusão: Os resultados indicam que, para pacientes em fases avançadas da DA, testes cognitivos apropriados e escalas funcionais baseadas no desempenho são úteis na avaliação mais acurada do estadiamento da doença e acompanhamento de sua progressão.

Wajman JR, et al. / Rev Psiq Clín. 2014;41(1):5-8

Palavras-chave: Doença de Alzheimer, demência, cognição, capacidade funcional.

\section{Introduction}

Cognitive deficits severe enough to interfere with instrumental and basic activities of daily living are a main clinical finding in Alzheimer disease (AD), and once detected at the patient evaluation it might be an indication not only of the possibility of dementia, but also of its severity ${ }^{1}$, though with disease progression tools to evaluate cognition and functionality have limited positive and negative values ${ }^{2}$.

Aside well-known aspects of cognition, in 1980 World Health Organization, trying to find a classification for functioning, included different aspects of functionality: 1) physiological and cognitive capacities; 2) capacity to undertake activities and 3) capacity to keep social roles ${ }^{3}$. This was an important step for the definition, but did not solved the conceptual terminological issue, more so with regard to the effect of disease on the subjects functional behaviour, since the concepts of lesion, incapacity and handicap were left out.
This said, the concept of functionality may be redefined as the quality of participation of an individual in occupations meaningful at the personal and cultural level, for which the understanding of the interaction between this individual and the environment is essential. In summary, functionality considered as a result requires an evaluation that takes in consideration not only dominions. This is possible if functionality is conceived with the incorporation of meaning, temporality, and the coexistence of function with dysfunction, considering previous education level ${ }^{4}$ in different contexts, beyond the mere metrical identification of cognitive incapacities ${ }^{5}$.

For subjects in advanced stages of dementia almost all the tools now available do not access adequately the performance and are not enough to serve as a follow up measure of disease evolution' ${ }^{6}$. The main objective of this investigation is the adaptation and study of the correlation among tools specific for the evaluation of $\mathrm{AD}$ with regard to cognition objectively evaluated and functional capacity evaluated by static scales versus ecological performance. 


\section{Methods}

\section{Participants}

For this transversal investigation 95 subjects with AD of both genders in moderate to severe stage along their caregivers were included. All participants were followed at the Severe Dementia Outpatients Clinic (Behavioural Neurology Section) and Brain Aging Group (Nudec) - Federal University of São Paulo (Unifesp), and, at the time of inclusion all fulfilled criteria for probable AD according to DSM-IV?.

For this investigation were considered as exclusion criteria: lack of a caregiver with a minimum conviviality of four days per week; illiterates; visual, auditory or motor limitation severe enough to hamper the performance; evidence of vascular brain insult in the last 12 months; chronic treatment for any neurological or psychiatric condition superimposed to AD; Mini-mental State Examination MMSE) under or above 5-15; CDR 1.

For the participation in this investigation all caregivers or a legal representative signed a Free and Informed Consent on details about the study methods and the objectives to be attained, the right to study results, and results confidentiality. The investigation was approved by Unifesp Institutional Review Board (register 1373/09)

\section{Instruments}

As tools for screening and staging for this study were used Clinical Dementia Rating - $\mathrm{CDR}^{8}$, standard $\mathrm{MMSE}^{9}$, Functional Assessment Staging Test - FAST ${ }^{10}$ in its subdivisions of stages 5 (moderate), 6 (moderately severe) and 7 (severe). With regard to cognitive evaluation the protocol include the Severe Mini-mental State Examination - MMSEsev ${ }^{11}$; the Severe Impairment Battery - SIB-8 ${ }^{12}$, modified for 8 items and the Test for Severe Impairment - TSI ${ }^{13}$.

For comparison of the cognitive evaluation with ecological functional performance it was used as a gold standard the Performance Test of Activities of Daily Living - PADL ${ }^{14}$, that was initially developed in partnership of researchers from London and New York for the evaluation of self-care in psychiatric settings. Actually this scale tries to evaluate 16 activities of daily life by the observation of real performance in a clinical setting, and takes about 20 minutes to be completed. This scale requires items like a glass, tissue paper, comb or hair brush, nail file, spoon, wall clock, telephone, paper and pencil among others and the performance is classified as 0) not correctly performed, 1) correctly performed or 9) unable.

After translation from English to Brazilian Portuguese, back translation, comparison and adaptation of the scales (JRW e PHFB), evaluation and joint decision among bilingual judges, natives or proficient and specialists in this area a scales pilot protocol was applied to evaluate the sensibility and cultural adequacy. In the field work each participant was interviewed just once with sessions duration ranging from 60 to 90 minutes. According to necessity there could be short breakings between tests, and, if necessary a session could be completed at another day.

\section{Statistical analysis}

Initially the statistical analysis of the data collected at this research was descriptive. For quantitative variables mean, median, standard deviation was calculated and bidimensional dispersion diagram graphics and box plots were done. Qualitative variables were analysed by absolute and relative frequency.

Inferential analyses were undertaken to accept or reject evidences shown by the descriptive analysis by point to point and interval estimative of Pearson linear correlation coefficient to quantify the linear correlation between tests and scales. Data were stored using the Windows Excel 2010. For statistical analysis the SPSS Pack, version 19.0 was used. Significance was set at $5 \%(\mathrm{p} \leq 0,05)$.

\section{Results}

This sample was composed by $33(34,7 \%)$ males and $62(65,3 \%)$ females with advanced $\mathrm{AD}^{7}$. Mean age was 74,7 years, ranging from 60 to 89 , with a standard deviation of 1.5 years. Mean disease duration was 7.3 years, ranging from 3 to 8 , with a standard deviation of 1.7 years.

The descriptive analysis of the sample according to screening tools, cognitive, and functional scales is shown in table 1 with raw values, mean, median, range, and standard deviation.

The estimates of Pearson linear correlation coefficients indicate that there is an increasing and statistically significant linear correlation between PADL and the other scales: for MMSEsev $(p=0,001)$ SIB- $8(p<0,001)$ and TSI $(p<0,001)$. It should be pointed out that while the numerical value is higher for PADL and SIB-8, the strength of the correlation between PADL and MMSEsev in the three intervals with $95 \%$ confidence is the statistically the same, though the "weaker" correlation, because there is an intersection among the respective intervals, as shown in table 2 and figure 1.

Table 1. CDR, FAST, MMSE, MMSEsev, SIB-8, TSI and PADL distribution between sample subjects

\begin{tabular}{|c|c|c|c|}
\hline CDR & Moderate & 22 & $23.2 \%$ \\
\hline & Severe & 73 & $76.8 \%$ \\
\hline \multirow[t]{3}{*}{ FAST } & Moderate (5) & 16 & $16.8 \%$ \\
\hline & Severely moderate (6) & 52 & $54.7 \%$ \\
\hline & Severe (7) & 27 & $28.4 \%$ \\
\hline \multirow[t]{6}{*}{ FAST } & 5 & 16 & $16.8 \%$ \\
\hline & $6 \mathrm{~A}$ & 21 & $22.1 \%$ \\
\hline & $6 \mathrm{~B}$ & 15 & $15.8 \%$ \\
\hline & $6 C$ & 16 & $16.8 \%$ \\
\hline & $7 \mathrm{~A}$ & 15 & $15.8 \%$ \\
\hline & $7 \mathrm{~B}$ & 12 & $12.6 \%$ \\
\hline \multirow[t]{4}{*}{ MMSE } & Average & \multicolumn{2}{|c|}{9.6} \\
\hline & Median & \multicolumn{2}{|c|}{10.0} \\
\hline & Minimum-maximum & \multicolumn{2}{|c|}{$5.0-15.0$} \\
\hline & Standard deviation & \multicolumn{2}{|c|}{3.0} \\
\hline \multirow[t]{4}{*}{ MMSEsev } & Average & \multicolumn{2}{|c|}{20.7} \\
\hline & Median & \multicolumn{2}{|c|}{21.0} \\
\hline & Minimum-maximum & \multicolumn{2}{|c|}{$12.0-30.0$} \\
\hline & Standard deviation & \multicolumn{2}{|c|}{4.2} \\
\hline \multirow[t]{4}{*}{ SIB-8 } & Average & \multicolumn{2}{|c|}{13.8} \\
\hline & Median & \multicolumn{2}{|c|}{14.0} \\
\hline & Minimum-maximum & \multicolumn{2}{|c|}{$4.0-24.0$} \\
\hline & Standard deviation & \multicolumn{2}{|c|}{5.3} \\
\hline \multirow[t]{4}{*}{ TSI } & Average & \multicolumn{2}{|c|}{14,8} \\
\hline & Median & \multicolumn{2}{|c|}{15.0} \\
\hline & Minimum-maximum & \multicolumn{2}{|c|}{$5.0-23.0$} \\
\hline & Standard deviation & \multicolumn{2}{|c|}{5.8} \\
\hline \multirow[t]{4}{*}{ PADL } & Average & \multicolumn{2}{|c|}{9.6} \\
\hline & Median & \multicolumn{2}{|c|}{9.0} \\
\hline & Minimum-maximum & \multicolumn{2}{|c|}{$5.0-16.0$} \\
\hline & Standard deviation & \multicolumn{2}{|c|}{3.2} \\
\hline
\end{tabular}

CDR: Clinical Dementia Rating; FAST: Functional Assessment Staging Test; MMSE: Mini-Mental State Examination; MMSEsev: Severe Mini-mental State Examination; SIB-8: Severe Impairment Battery; TSI: Test for Severe Impairment; PADL: Performance Activities of Daily Living. 
Table 2. Point and interval estimates of Pearson's linear correlation coefficient between PADL and MMSEsev, SIB-8 and TSI

\begin{tabular}{|l|c|c|c|c|}
\hline & $\mathrm{n}$ & Coefficient $^{\mathrm{a}}$ & Interval $^{\mathrm{b}}$ & $\mathrm{p}$ \\
\hline PADL and MMSEsev & 95 & 0.323 & {$[0.130 ; 0.492]$} & 0.001 \\
\hline PADL and SIB-8 & 95 & 0.588 & {$[0.438 ; 0.706]$} & $<0.001$ \\
\hline PADL and TSI & 95 & 0.531 & {$[0.369 ; 0.662]$} & $<0.001$ \\
\hline
\end{tabular}

aPearson's linear correlation coefficient; $b$ 95\% confidence interval for Pearson's linear correlation coefficient.

PADL: Performance Activities of Daily Living; MMSEsev: Severe Mini-Mental State Examination; SIB-8: Severe Impairment Battery; TSI: Test for Severe Impairment.

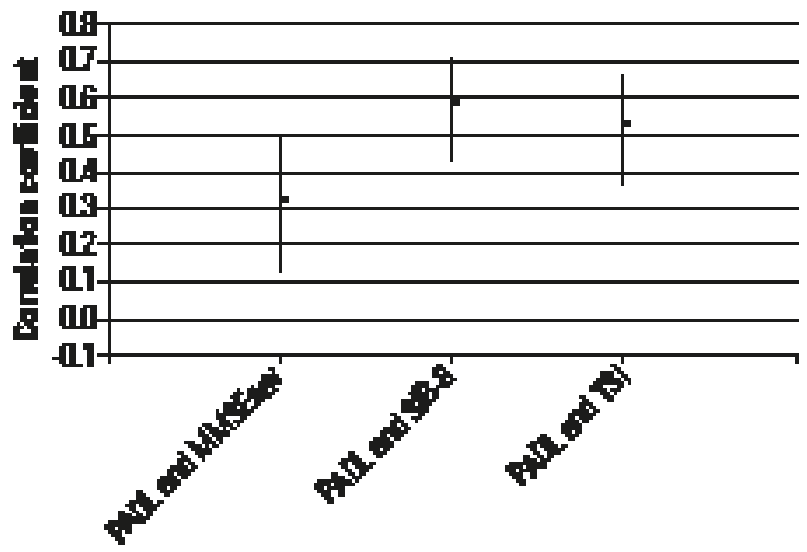

Figure 1. Point and interval estimates of Pearson's linear correlation coefficient between PADL and MMSEsev, SIB-8 and TSI.

PADL: Performance Activities of Daily Living; MMSEsev: Severe Mini-Mental State Examination; SIB-8: Severe Impairment Battery; TSI: Test for Severe Impairment.

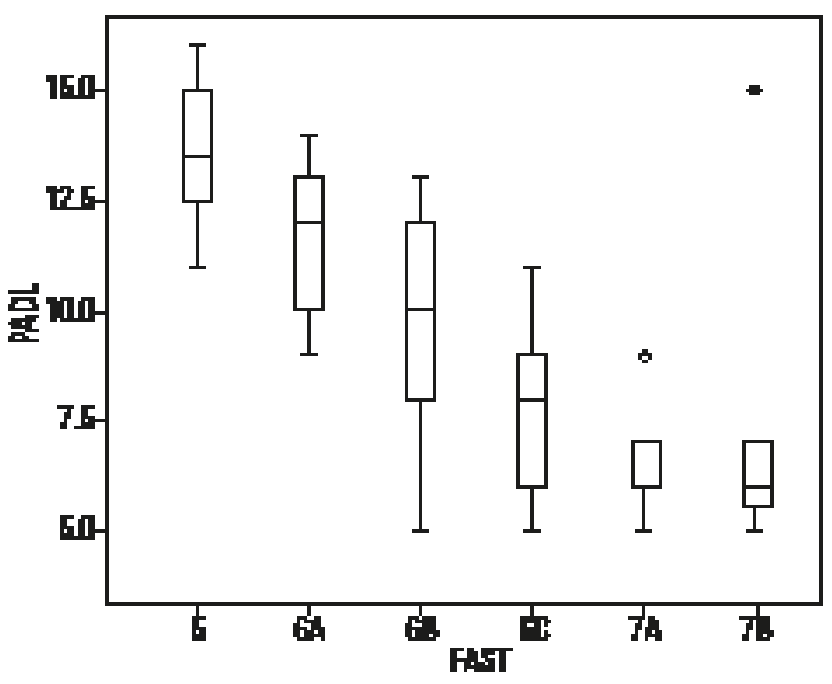

Figure 2. PADL boxplot, according to stratified FAST.

PADL: Performance Activities of Daily Living; FAST: Functional Assessment Staging Test; ${ }^{\circ}$ : possible outlier; ${ }^{*}$ probable heavy-tailed value.

The stratification of subcategories of the static functional scale FAST, PADL, MMSEsev, SIB-8 and TSI were also analyzed with regard to parametric and nonparametric aspects (distribution and variance). Figure 2 shows the summary of measures in these scales, according to each FAST subcategory. Inferential results showed that subjects in each of the six different FAST subcategories $(5,6 \mathrm{~A}, 6 \mathrm{~B}, 6 \mathrm{C}, 7 \mathrm{~A}$, and $7 \mathrm{~B})$ presented a specific and statistically significant performance in each of these subcategories in the functional ecological PADL ( $\mathrm{p}<$ $0,001)$ and in the cognitive tests MMSEsev ( $p<0,001)$, SIB- 8 ( $p<$ $0,001)$ and TSI $(\mathrm{p}<0,001)$. As such, the comparison and correlation results between FAST subcategories 5 to $7 \mathrm{~B}$ showed a higher statistical significance $(\mathrm{p}<0,001)$ according to the functional ecological scale used as the gold standard for this investigation (PADL) and the cognitive tests (MMSEsev, SIB-8 e TSI).

\section{Discussion}

This investigation tried to relate cognitive performance, as evaluated by tools specific for advanced dementia, with functional scales selected according to differences in the psychometric structure. Both CDR and FAST might be considered static or categorical scales, while PADL evaluates more dynamic aspects of functionality, since its method is the observation of the realization or simulation of common activities of daily living that the subject does in his/her ecological environment. The paradigm here is the identification and analysis of possible gaps between patient capacity as referred by the caregiver and the real performance, as evaluated by the examiner.

As it was initially hypothesized, the functional evaluation based in the subject's actual performance had a positive and statistically significant correlation with static functional scales and cognitive tests, Additionally, in the scale based on the caregiver information there was a correlation between the subcategories and the results on the ecological scale, once triangulated with MMSEsev, SIB-8, and TSI and disease stage, in the sense that the worse the performance on these three tests, the higher the disease worsening in the functional scale, thus characterizing a linear relation among the tools used here.

Though advanced dementia is an important issue, there is a lack of investigation on this subject. Investigations on cognition and functionality in advanced $\mathrm{AD}$ are scarce. Considering the bulk of investigations to validate tools appropriate for this group of patients ${ }^{15-17}$, none was specific for severe dementia. Only one research including $\mathrm{AD}$ subjects in varying stages followed in three different centers were evaluated about functional and motor aspects ${ }^{18}$, but even so, functional scales were based on caregiver information and there were more subjects with mild than with moderate or severe disease.

On the other hand, important contributions on the relationship between functionality and cognitive impairment are present in the literature. Niegovan et al. ${ }^{19}$ analyzed a cohort of more than five thousand and eight hundred elderly living in the community during the five years period. This was the first and most representative prospective study linking function and cognition patterns with incidental loss during the aging process. Such estimates currently reflect on family planning and multidisciplinary monitoring of the Canadian national program of public health policies.

Another study, using a refined and elegant prospective design, compared cognitive, behavioral and functional findings in the initial evaluation and after 24 months ${ }^{20}$. In this case, after compared correlations and linear regressions, authors concluded that during follow-up a positive association between cognitive abilities and instrumental activities tended to decrease, while direct relationship between instrumental impact and neuropsychiatric disorders increases. Unfortunately, the study did not include patients with severe dementia.

$\mathrm{AD}$ in advanced stages is an important social responsibility, with implications for prevalence, direct and indirect costs and the suffering to family and caregivers. As pointed before ${ }^{21}$, methods for intervention could improve quality of life for both patient and family, bringing information on cognition and functionality still preserved that are not assessed due to inadequate methods of evaluation.

There are limitations in this study that should be pointed. Though this was a large sample, this was not a stratified sample from the general population of severe dementia patients, so these results might not be representative of this population as a whole. It should be stressed however that our results are in accordance with the results of comparable studies. Though frequent, were not included in this investigation subjects with neuropsychiatric symptoms, which could be a bias with regard to performance in the scales. In future studies 
samples with these conditions and MMSE score under 5 should be included and compared. This being a transversal study, results here described do not reflect the same effects for the same subject in other stages of the disease, something that only a prospective study could address.

In summary, taking an ecological functional scale, the PADL, as gold standard it could be concluded that its correlation with scales here classified as static, because they are based on the informant's opinion (CDR and FAST), and with three cognitive scales (MMSEsev, SIB-8 and TSI) was appropriate and reliable in the objective evaluation of $\mathrm{AD}$ subjects with severe dementia.

\section{References}

1. Ruitenberg A, Kalmijn S, de Ridder MA. Prognosis of Alzheimer's disease: the Rotterdam Study. Neuroepidemiology. 2001;20:188-95.

2. Sevush S, Peruyera G, Bertran A, Cisneros W. A three-factor model of cognition in Alzheimer's disease. Cogn Behav Neurol. 2003;16:110-7.

3. World Health Organization. International Classification of Impairments, Disabilities and Handicaps (ICIDH). Geneva: OMS; 1980.

4. Sales MV, Suemoto CK, Nitrini R, Jacob-Filho W, Morillo LS. A useful and brief cognitive assessment for advanced dementia in a population with low levels of education. Dement Geriatr Cogn Disord. 2011;32:295-300.

5. Campbell AJ, Busby WJ, Robertson MC, Lum CL, Langlois JA, Morgan FC. Disease, impairment, disability and social handicap: a community based study of people aged 70 years and over. Disabil Rehabil. 1994;16:72-9.

6. Knopman DS, DeKosky ST, Cummings Jl. Practice parameter: diagnosis of dementia (an evidence-based-review). Report of the Quality Standards Subcommittee of the American Academy of Neurology. Neurology. 2001;56:1143-53.

7. American Psychiatric Association. Diagnostic and Statistical Manual of Mental Health Disorders (4th Ed). Washington DC; 1994.

8. Folstein MF, Folstein SE, McHugh PR. "Mini-Mental State": a practical method of grading the cognitive state of patients for the clinician. J Psychiatr Res. 1975;12:189-98.

9. Morris JC. The Clinical Dementia Rating (CDR): current version and scoring rules. Neurology. 1993;43:2412-4.
10. Reisberg B. Functional Assessment Staging (FAST). Psychopharmacol Bull. 1998;24:653-9.

11. Harrell LE, Marson D, Chatterjee A, Parrish JA. The Severe Mini-Mental State Examination: a new neuropsychologic instrument for the bedside assessment of severely impaired patients with Alzheimer disease. Alzheimer Dis Assoc Disord. 2000;14:168-75.

12. Schmitt FA, Ashford W, Ernesto C, Saxton J, Schneider LS, Clark CM, et al. The severe impairment battery: concurrent validity and the assessment of longitudinal change in Alzheimer's disease. Alzheimer Dis Assoc Disord. 1997;11:51-6.

13. Albert $M$, Cohen $C$. The Test for Severe Impairment: an instrument for the assessment of patients with severe cognitive dysfunction. J Am Geriatr Soc. 1992;40:449-53.

14. Kuriansky JA, Gurland B. The performance test of activities of daily living. Int J Aging Hum Dev. 1976;7:343-52.

15. Bertolucci PHF, Brucki S, Campacci SR, Juliano Y. The Mini-Mental State Examination in an outpatient population: influence of literacy. Arq Neuropsiquiatr. 1994;52:1-7.

16. Bahia VS, Carthery-Goulart MT, Novelli MM, Kato-Narita EM, Areza-Fegyveres R, Caramelli P, et al. Functional disability in Alzheimer's disease: a validation study of the Brazilian version of Disability Assessment for Dementia (DAD-Br). Alzheimer Dis Assoc Disord. 2010;24:291-5.

17. Pereira FS, Oliveira AM, Diniz BS, Forlenza OV, Yassuda MS. Cross-cultural adaptation, reliability and validity of the DAFS-R in a sample of Brazilian older adults. Arch Clin Neuropsychol. 2010;25:335-43.

18. Zidan M, Arcoverde C, Bom de Araújo, N, Vasques P, Rios A, Lakz J, et al. Alterações motoras e funcionais em diferentes estágios da doença de Alzheimer. Rev Psiq Clín. 2012;39(5):161-5.

19. Niegovan V, Hing MM, Mitchell SL, Molnar FJ. The hierarchy of functional loss associated with cognitive decline in older persons. J Gerontol A Biol Sci Med Sci. 2001;56:638-43.

20. Monaci L, Morris RG. Neuropsychological screening performance and the association with activities of daily living and instrumental activities of daily living in dementia: baseline and 18-to 24-month follow-up. Int J Geriatr Psychiatry. 2011;27:197-204.

21. Wajman JR, Bertolucci PHF. Comparison between neuropsychological evaluation instruments for severe dementia. Arq Neuropsiquiatr. 2006;64:736-40. 